The economic position of women has undergone rapid changes in Hong Konghis tr a the-published version period 1976-1986, the female-male earnings ratio rose dramatically by about ten percentage points (Lui and Suen 1993). What happened since 1986? Different fragments of evidence point to different answers. According to the General Household Surveys, the ratio of female-male median earnings rose steadily from .67 in 1986 to .73 in $1991 .{ }^{1}$ On the other hand, the average daily wages of female laborers in government building and construction projects remained stable at around 81 to 83 percent of male laborers' wages during the same period (Annual Digest of Statistics, 1992). Neither source, however, is comprehensive and detailed enough to capture an accurate picture of the economic situation of women. This paper uses the recently released 1991 Population Census one percent sample file to study the gender gap in Hong Kong. The paper is essentially an update on the information contained in Lui and Suen (1993; 1994).

To summarize the main results, I find that the female-male earnings ratio in 1991 remained virtually unchanged at .71 since 1986. The lack of improvement in the gender gap largely reflects the absence of any increase in the female labor force participation rate during that period. This paper also finds that the large gender gap associated with university graduates in Hong Kong can be attributed to the large number of highly educated but low paid Filipino domestic helpers in the territory.

\title{
1. The Earnings Gap
}

The data used in this study comes from the one percent random sample of the 1991 Population Census records. All government and private sector employees aged fifteen or above and with positive earnings are selected. Unlike previous censuses, the 1991 Census does not contain information about hours of work. So it is impossible to distinguish between full-time and part-time workers, nor is it possible to impute hourly wages for the workers. The sample contains 8976 female records and 13703 male records. For comparison, I have used the same selection criteria to draw a sample from the 1986 By-Census one percent file.

\footnotetext{
1 The calculation is based on unpublished GHS tabulations.
} 
A few (28) of the earnings records in the file are truncated at the top code of $\$ 99,998$. I use a log-normal approximation (see, for example, Hart 1990) to impute a conditional mean of $\$ 114,848$ to individuals whose earnings are top-coded. For the 1986 file, the imputed conditional mean is $\$ 111,908$.

In 1991 the mean male monthly earning was $\$ 8,109$ while mean female earning was $\$ 5,759$. This gives an earnings ratio of .71. For the year 1986 the female-male earnings ratio was also .71. Thus - in stark contrast to the period 1976 to 1986 - the average pay of women relative to men did not show any significant increase since 1986.

The difference in mean log earnings between men and women in 1991 was -.30 with a standard error of .0087. On the surface this seems to be an improvement over the log earnings gap of -.34 (s.e. $=.0089)$ in 1986. However, there were also changes in the dispersion of earnings during the period. The standard deviation of female log earnings fell from .66 to .63, while that of male log earnings rose from .62 to .66. Since the logarithmic transformation is concave, a fall in the dispersion tends to increase the mean, while a rise in dispersion tends to lower it (Jensen's inequality). Thus the earnings ratio cannot be simply computed from the exponent of the difference in mean log earnings. If log earnings are normally distributed, the mean earnings ratio can be approximated by $\exp \left\{\mu_{f}-\mu_{m}+1 / 2\left(\sigma_{f}^{2}-\sigma_{m}^{2}\right)\right\}$, where $\mu$ and $\sigma$ are the mean and standard deviation of log earnings and the subscripts indicate females and males. Making this adjustment, the measured earnings gap is virtually unchanged (at .73) between the two years.

Figure 1 shows that female-male earnings ratios in 1986 and in 1991 by deciles. There was a marked improvement in the ratio for women near the lower end of the distribution, while the ratio deteriorated for women in the highest income bracket. On closer examination it is found that, compared to other women, low income women experienced higher than average earnings growth since 1986. (This also explains why the female wage dispersion fell.) On the other hand, though women in the 10th earnings decile did not experience below-average earnings growth, the earnings of their male counterpart increased faster than average (which explains why the male wage dispersion increased). Consequently the income of women in this group fell relative to men. 


\section{The Occupation Gap}

The occupation classifications used in the 1991 Census were based on a set of criteria different from those used in previous censuses. Thus 1991 and 1986 occupation codes are not comparable and only the 1991 data are presented.

The structure of occupation is quite different between the sexes. Based on 30 twodigit occupations, the index of occupational dissimilarity, defined as the sum of the absolute difference in the fraction of employed females $\left(f_{i}\right)$ and the fraction of employed men $\left(m_{i}\right)$ in different occupations (i.e., $\left.\sum_{i}\left|f_{i}-m_{i}\right| / 2\right)$, is equal to .40 . This means that at least forty percent of all female (or male) workers would have to switch occupations if the distribution of occupations among females were to be the same as that among males.

The index of occupational dissimilarity does not capture the full picture of occupational segregation because it ignores the systematic differences in pay across occupations. Compared to men, women tend to be more concentrated in low pay jobs. If $y_{i}$ is the average pay of occupation $i$, the average occupational position of women relative to men can be measured by $\sum_{i} f_{i} y_{i} / \sum_{i} m_{i} y_{i}$. This index is equal to .89 in 1991.

Even if the structure of occupation were the same between the sexes, however, women would still earn less than men on average. This is because the average earning for

females within occupation $i\left(y_{i}^{f}\right)$ is less than the average earning for men in the same occupation $\left(y_{i}^{m}\right)$. For example, female clerks make 88 percent as much as male clerks, and female machine operators and assemblers make 58 percent as much as their male counterparts. If $s_{i}$ denotes the share of all employed workers in occupation $i$, the ratio $\sum_{i} s_{i} y_{i}^{f} / \sum_{i} s_{i} y_{i}^{m}$ indicates what the earnings gap would be if there were no difference in occupation structure. This ratio turns out to be .75. In other words, after controlling for occupations, the female earnings gap would fall from 29 percent to 25 percent.

\section{Differential Returns to Experience}

Human capital earnings regressions can be used to investigate the effect of demographic factors on the gender earnings gap. I specify log earnings as a linear function of sex, mar- 
ital status, place of birth, and six education levels interacted with quartics in potential experience. $^{2}$ The coefficient on the dummy variable for female is estimated to be -.30 $($ s.e. $=.0071)$. Compared to the raw earnings gap of -.30 , this means that differences in observable labor market characteristics between the sexes are unimportant in explaining the differences in their pay.

One problem of using Census surveys is that actual work experience is not observable. The variable "potential experience" 3 is a poor proxy for actual experience because of women's intermittent participation in the labor force. To correct for this bias, I construct a variable "cumulative experience." The "cumulative experience" for a person with $t$ years of potential experience is defined to be $\sum_{s \leq t} \operatorname{LFPR}(s)$, where $\operatorname{LFPR}(s)$ is the sexspecific labor force participation rate for people with $s$ years of potential experience. The construction of this variable assumes all women spend, say, fifty percent of the year working if the labor force participation rate is fifty percent. In fact there is considerable heterogeneity in individual labor participation decisions, and "cumulative experience" will understate the true years of work experience of the working men and women in the sample.

When the variable "cumulative experience" is used instead of "potential experience," the difference in mean number of years of experience between men and women increases from 3.46 to 6.73. However, even with this adjustment, the coefficient on the variable "female" is only changed slightly from -.30 to -.29 (s.e. $=.0077) .{ }^{4}$ gender gap, it is Since "potential experience" and "cumulative experience" are the upper and lower bound estimates of true work experience, the regression exercise suggests that differences in the number of years of work experience cannot account for a significant part of the gender gap.

If intermittent labor force participation does adversely affect women's earnings, as argued by Mincer and Polachek (1974), the main channel of the effect cannot be through

2 The full set of regression results are available from the author upon request.

3 Here potential experience is defined as $\max \{0$, age $-\max \{15$, schooling +6$\}\}$.

4 The difference in estimated coefficients of .01 is 1.3 times the standard error. Substantively, this difference is unimportant as it accounts for only about 3 percent of the gender gap. 
reduced number of years of work. More subtle, and less observable, mechanisms such as accelerated depreciation of skills and diminished career orientation may be at work that slow down the accumulation of human capital. Such factors would be reflected in the shape of the experience-earnings profile. Figure 2(a) shows the estimated experienceearnings profiles for the average man and the average woman; ${ }^{5}$ and Figure 2(b) shows the profiles when "cumulative experience" is used in place of "potential experience." In both panels, there is little gender pay gap for new entrants to the labor market. However, as earnings rise much less steeply for women than for men, the gender gap widens progressively until it reaches a peak for people with about twenty years of potential experience. For a locally-born, married woman with secondary education and twenty years of potential experience, her predicted earning is .28 log points below that of her male counterpart. If her experience-earnings profile were the same as that of a comparable man, her predicted earning would only be $.08 \mathrm{log}$ points below his. Differences in the slope of the experience-earnings profiles therefore account for a major part of the female earnings gap.

The relationship between labor force participation and earnings can be seen clearly in Figure 3. Panel (a) of the figure shows the close concordance between differential labor force participation and differential earnings for each age group between fifteen and sixty-five. ${ }^{6}$ The simple correlation coefficient of the two variables is $.86(t=11.96)$. Figure 3(b) depicts the relationship from another perspective. Between 1986 and 1991, the female labor force participation rate rose for the younger age groups but fell for the older groups. During the same period, the growth in earnings for younger female workers was faster than that for older workers. The simple correlation between the change in labor force participation rate and the change in log earnings is .29 with a $t$-statistic of 2.13 .

Figure 3(b) also sheds some light on the reason for the lack of improvement in the

5 Earnings of the "average man" refer to predicted log earnings with all explanatory variables other than experience held at the sample average values for men; similarly for the "average woman."

6 The population base used to calculate the labor force participation rate here does not include full time students. 
gender earnings gap since 1986. A regression of the change in log earnings on the change in labor force participation rate gives a coefficient of .55 (s.e. $=.26)$. From 1986 to 1991, the female labor force participation rate actually fell from .51 to .48. If the change in female labor force participation were the same as the period 1976-86, it would be 6.07 percentage points higher than its actual level in 1991. The higher growth in female earnings associated with the higher female labor force participation would have reduced the gender earnings gap by 3.35 log points.

\section{Differential Returns to Education}

In 1991 the average number of years of schooling for working women was 9.45, and working men had on average only 9.15 years of education. While the level of education of men and women is essentially at parity, substantial differences in the returns to education remain. Figure 4 shows the log earnings of the average men and women at different schooling levels. One can see that the premium on secondary education is higher for women than for men. On the other hand the premium on university degrees is higher for men than for women.

To further investigate the effect of education on the gender gap, I divide the sample into six schooling levels and estimate an earnings regression for each sub-sample. Table 1 shows the results. Focusing on the full sample first, the column "Raw Gap" refers to the difference in mean log earnings, and the column "Adjusted Gap" refers to the coefficient on the dummy variable for female in an earnings regression which controls for place of birth, marital status, and potential experience. The higher premium on secondary education for females is reflected in the smaller earnings gap among workers who finished secondary education. Contrary to human capital theory, however, the female earnings gap does not fall monotonically with education level. In particular the earnings gap is largest among the group of degree holders, even though female degree holders have a higher labor force participation rate than females with lesser education.

In another research project on domestic helpers in Hong Kong (Suen 1994), I found that a substantial fraction of the Filipino maids have university degrees. In the present 
sample, 123 out of the 563 female workers with university degrees are from the Philippines. While the released 1991 Census file does not allow identification of domestic helpers through two-digit occupation codes, the category "sales and services elementary occupations" (code 91) includes domestic helpers. Among female workers with university degrees, there are 113 whose occupation code is 91 ; of these, only 4 are born in Hong Kong, China, or Macau. The average earnings of degree holders in "elementary occupations" is less than half of other degree holders. The presence of such highly educated but low pay female workers can significantly affect the estimate of the returns to university education for females. ${ }^{7}$ To adjust for this, the earnings regressions are re-estimated after excluding workers who are born outside Hong Kong, China, or Macau. With the restricted sample, Table 1 shows that the raw earnings gap for degree holders shrinks from -.57 to -.19 , and the adjusted earnings gap changes from -.48 to $-.13 .{ }^{8}$ The estimated earnings gap for people with secondary education or below remains virtually unchanged. This exercise demonstrates the serious bias that may arise if workers born in Hong Kong, China, or Macau and workers born elsewhere are treated as homogeneous.

7 Among female degree holders, the average earning of those who were born in Hong Kong, China, or Macau was $84 \mathrm{log}$ points higher than that of those born elsewhere. Among male degree holders, on the other hand, those born in Hong Kong, China, or Macau earned 66 log points less than those born elsewhere. Thus using dummy variables for place of birth without interaction terms in an earnings regression will not capture the differential effect of the foreign maids on average female earnings.

8 Similarly, for the year 1986, the estimated female earnings gap among university graduates shrinks from -.38 to -.13 when foreign born workers are excluded. 


\section{References}

Hart, P.E. "Lognormal Distribution." Pp. 145-147 in J. Eatwell, M. Milgate and P. Newman, eds., The New Palgrave: Econometrics. London: MacMillan, 1990.

Lui, Hong-Kwong and Wing Suen. "The Narrowing Gender Gap in Hong Kong: 19761986." Asian Economic Journal 7 (July 1993): 167-180.

—. "The Structure of the Female Earnings Gap." Hong Kong Economic Papers 23 (1994): 15-29.

Mincer, Jacob and Solomon Polachek. "Family Investments in Human Capital Earnings for Women.” Journal of Political Economy 82 (1974 Supplement): S76-S110.

Suen, Wing. "Market-Procured Housework: The Demand for Domestic Servants and Female Labor Supply." Labour Economics 1 (September 1994): 289-302. 


\title{
GENDER GAP IN HONG KONG: AN UPDATE
}

\author{
Wing Suen* \\ University of Hong Kong
}

(July 1995)

* I thank Julia Cheung for able research assistance. 


\section{Table 1}

\section{Female Earnings Gap by Education}

\begin{tabular}{lcccc}
\hline \multirow{2}{*}{ EDUCATION } & \multicolumn{2}{c}{ Full Sample } & \multicolumn{2}{c}{ Restricted Sample } \\
& Raw Gap Adjusted Gap & Raw Gap Adjusted Gap \\
\hline \multirow{2}{*}{ No Schooling } & -.40 & -.41 & -.41 & -.41 \\
& $(.027)$ & $(.027)$ & $(.028)$ & $(.028)$ \\
Primary & -.43 & -.47 & -.42 & -.47 \\
& $(.014)$ & $(.013)$ & $(.014)$ & $(.014)$ \\
Lower Secondary & -.39 & -.39 & -.38 & -.38 \\
& $(.015)$ & $(.015)$ & $(.016)$ & $(.015)$ \\
Upper Secondary & -.19 & -.15 & -.17 & -.14 \\
& $(.012)$ & $(.011)$ & $(.012)$ & $(.011)$ \\
Post Secondary & -.25 & -.15 & -.15 & -.08 \\
& $(.023)$ & $(.021)$ & $(.023)$ & $(.020)$ \\
Degree & -.58 & -.48 & -.19 & -.13 \\
& $(.045)$ & $(.042)$ & $(.047)$ & $(.040)$ \\
\hline
\end{tabular}

Standard errors are in parentheses. 
FIGURE 1

Female-Male Earnings Ratio by Deciles

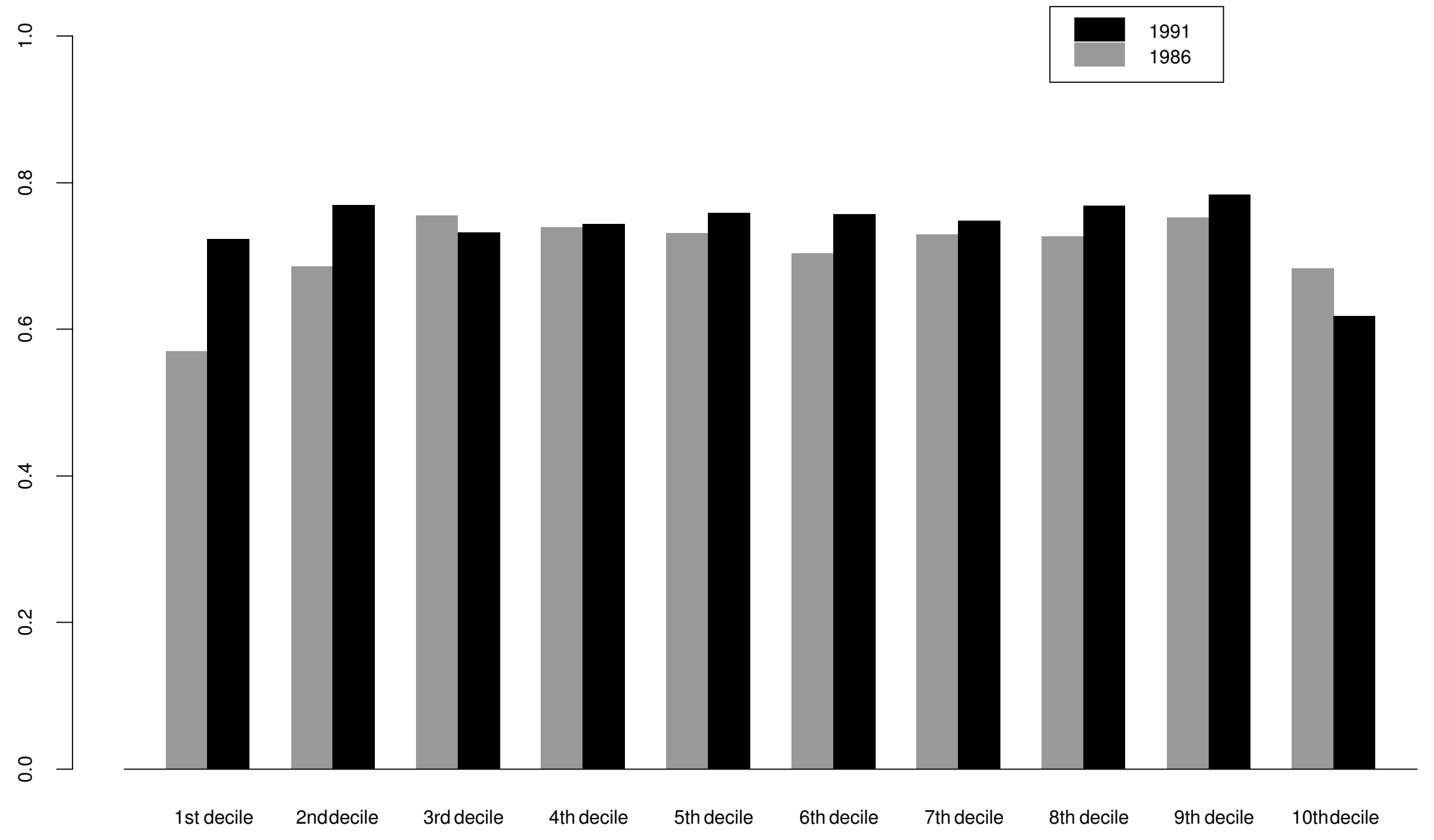




\section{FIGURE 2 \\ Experience-Earnings Profiles}

(a) Potential Experience

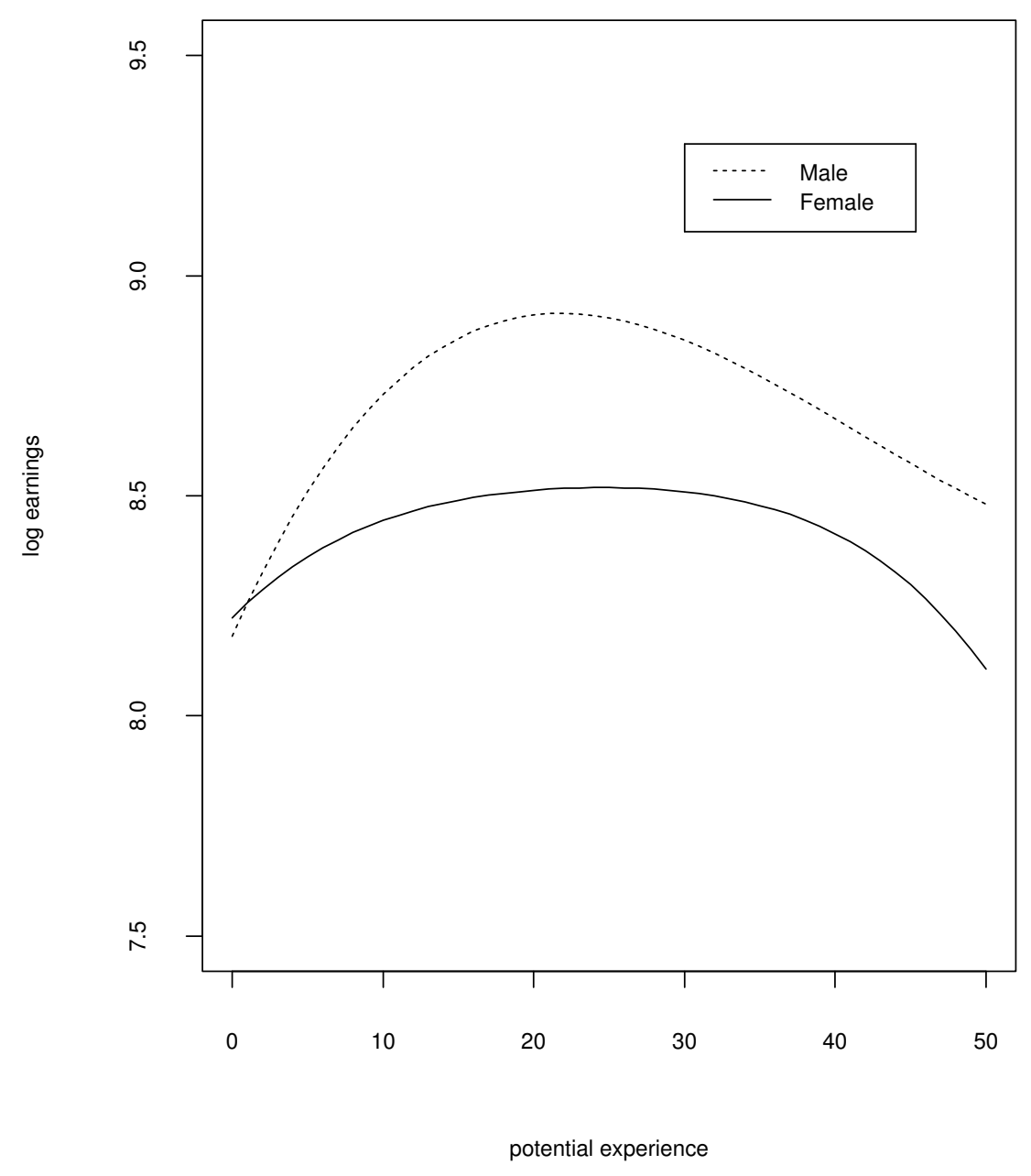

(b) Cumulative Experience

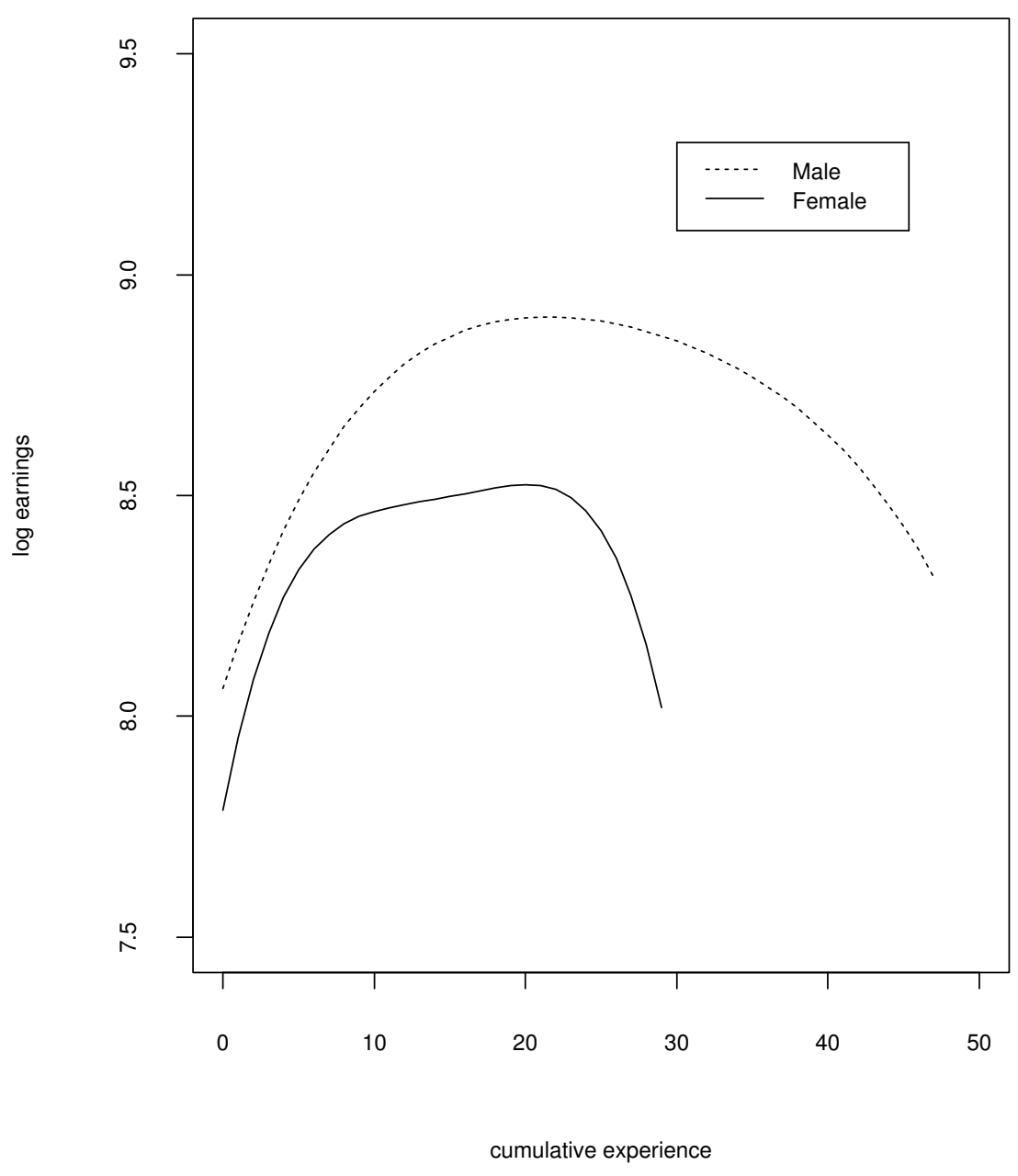




\section{FIGURE 3 \\ Labor Force Participation and Earnings}

(a) Difference between Men and Women, 1991

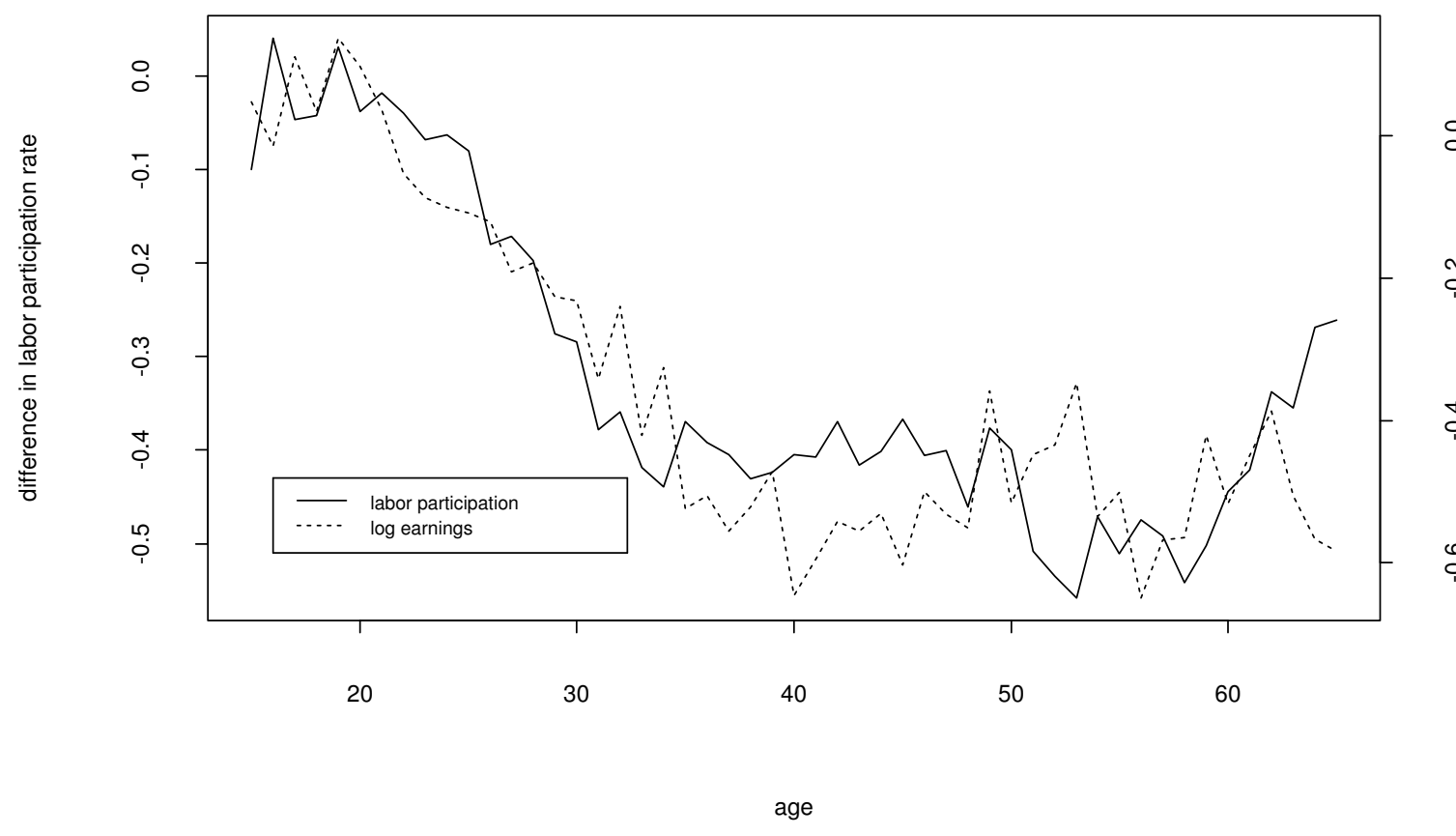

(b) Change from 1986 to 1991, Females

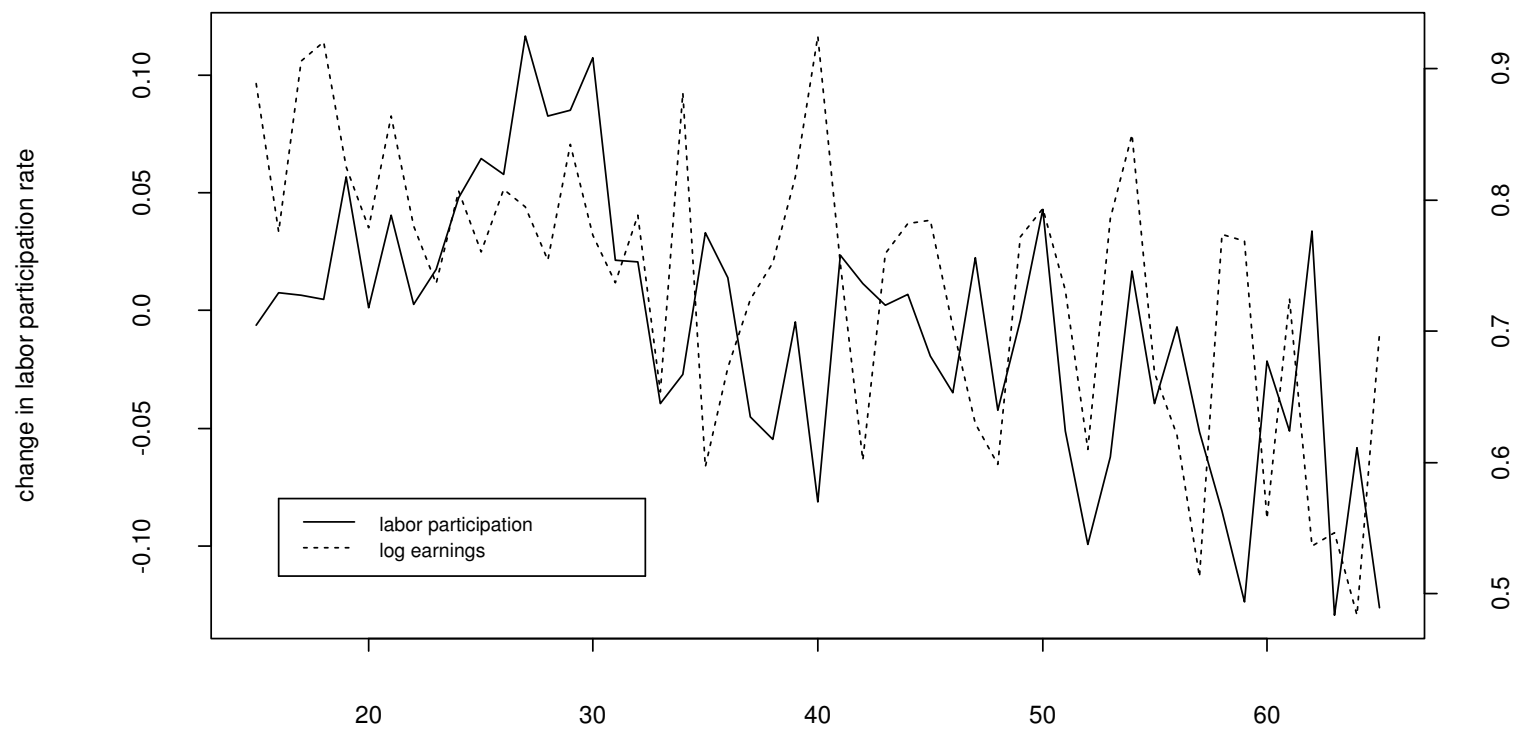




\section{FIGURE 4 Education and Earnings}

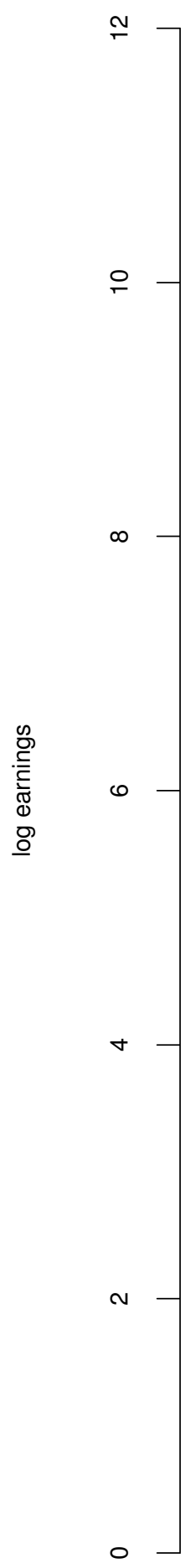

\begin{tabular}{|l|}
\hline degree \\
post secondary \\
upper secondary \\
lower secondary \\
primary \\
no schooling \\
\hline
\end{tabular}
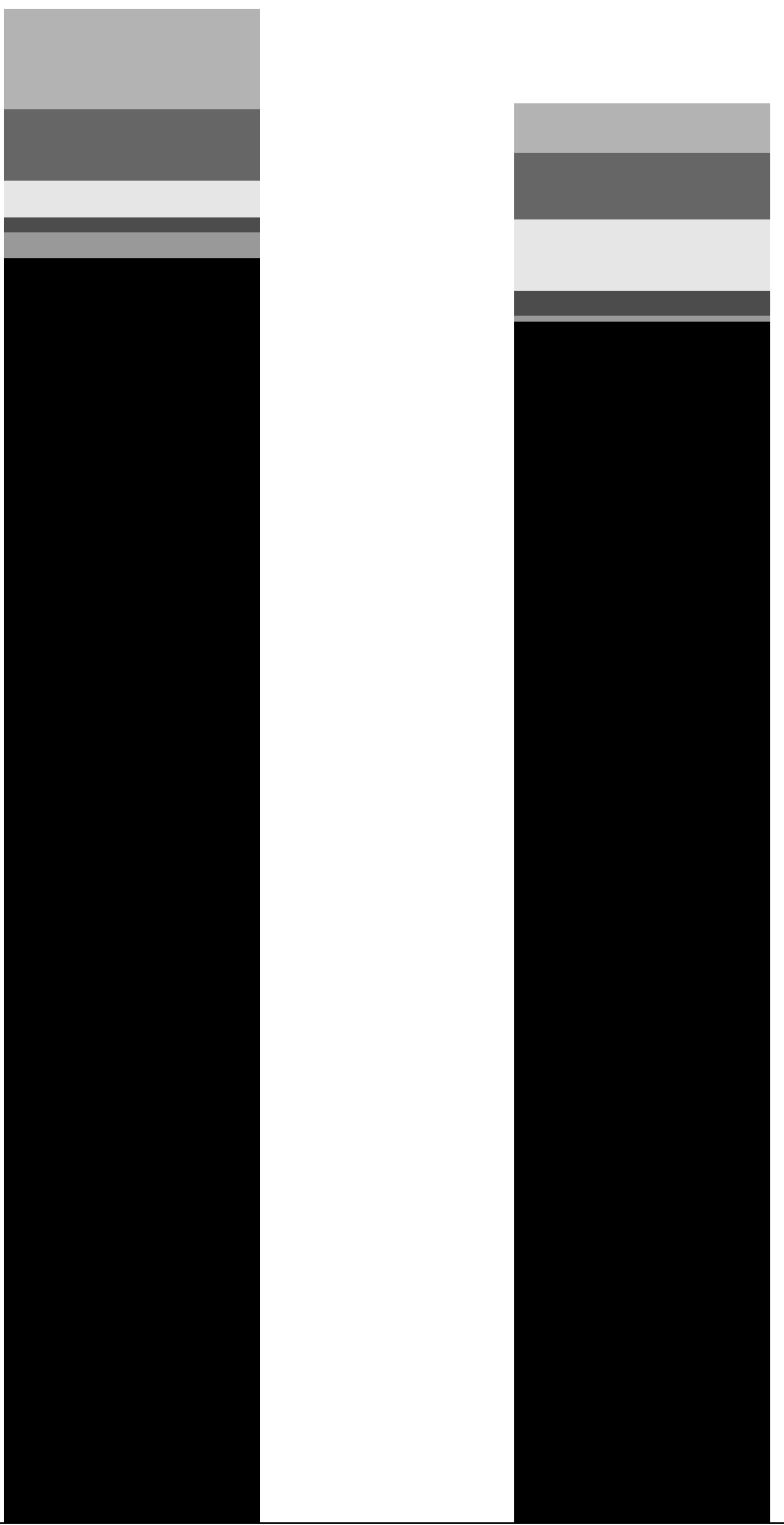